\title{
Falsos antropónimos en la toponimia española: Fuente de Mariguantes, Alto de Maripez, Mariagua*
}

\author{
False anthroponyms in Spanish toponymy. \\ Fuente de Mariguantes, Alto de Maripez, Mariagua
}

\author{
Emilio Nieto Ballester \\ Universidad Autónoma de Madrid
}

\begin{abstract}
RESUMEN: Toponimia y antroponimia son dos parcelas de los estudios de onomástica íntimamente relacionadas. Tenemos centenares de topónimos en los que aparece el antropónimo femenino María, Mari. Entre ellos hay algunos en los que aparece un segundo elemento, un apellido, de Mari o María un tanto sorprendente, como ocurre en casos como Mariguantes, Maripez, Mariagua. El trabajo muestra que hay que entender en estos ejemplos un primer elemento Mira-, con metátesis vocálica favorecida por la etimología popular. Otros topónimos españoles también ofrecen Paco y Juan como falsos antropónimos.
\end{abstract}

Palabras clave: toponimia, antroponimia, etimología popular.

ABSTRACT: This paper aims to show the depth of the relationship between place names and personal names in Spanish Onomastics. In Spanish place names the female name María or Mari (hypocoristic form) is frequently found. Among some of those names a second element is also present, a somewhat surprising surname of Mari or María which occurs in examples such as Mariguantes, Maripez, Mariagua. In our view there seems to have in fact been a first element Mira-, with vowel metathesis favored by folk etymology. Other Spanish place names also offer Paco and Juan as false anthroponyms.

Keywords: toponomastics, anthroponomastics, folk etymology.

\footnotetext{
* Este trabajo es parte del proyecto de investigación FFI2010-21807. Los topónimos citados lo son con indicación de municipio y provincia, salvo casos contados en que está clara su pertenencia provincial. Cuando coinciden los nombres del municipio y de la provincia se indican solamente una vez. El autor agradece las observaciones de los informantes de la revista, que han sido tenidas en cuenta en su mayor parte.
} 
La onomástica española, entendida como ese vasto campo de estudio lingüístico compuesto fundamentalmente de toponimia y antroponimia, plantea a menudo problemas de extraordinaria dificultad que difícilmente pueden ser resueltos en nuestro estado actual de conocimientos; en otras ocasiones, sin embargo, presenta problemas de una dificultad menor que no han sido abordados, a nuestro conocimiento, hasta la fecha como consecuencia del abandono a que ha estado sometida esta parcela de los estudios linguiísticos. El propósito de esta breve nota es llamar la atención sobre un hecho a nuestro juicio interesante, propio de la llamada "toponimia menor", esto es, de algunos de los millones de topónimos españoles que no lo son de núcleos de población y que, por ello mismo, son usualmente desatendidos.

\section{El ANTROPÓNIMO MARÍA, MARI EN LA TOPONIMIA ESPAÑOLA}

No es nada sorprendente la existencia en todo el dominio lingüístico español de centenares de topónimos de lugares menores que presentan antropónimos. Ello es natural, pues nada lo es más que el designar un lugar por el nombre de su propietario o, en un sentido más amplio, por el nombre de una persona que por cualquier razón ha estado vinculada a este lugar. Ello es así desde época romana, y probablemente lo fue aún antes. Esta conversión del antropónimo en topónimo, y también el proceso contrario ${ }^{1}$, es una de las fuentes de la estrecha vinculación, que a menudo sólo somos capaces de vislumbrar con dificultad, entre antroponimia y toponimia.

Así las cosas, uno de los nombres más frecuentes para mujer, María, bien en esta forma plena, bien en su forma hipocorística o apocopada en composición Mari, está documentado por todas partes en la formación de topónimos. Son centenares y centenares los topónimos de este tipo, topónimos que, en principio, no parecen tener mayor interés y plantear especial dificultad. Muchas veces aparece la forma del antropónimo en su forma hipocorística con una determinación añadida, que puede ser el apellido de la tal María, Mari, un apodo local, etc. Podemos citar muy fácilmente algunos casos, como Marigómez (Navarrevisca, Ávila), Dehesa Marigarcía (Ávila), Arroyo Marigarcía (Navalacruz, Ávila), Pico de Mari-Grande (Huertahernando, Guadalajara), Torre de Doña María (Andorra, Teruel), Casa de Mariantonia (Laspuña, Huesca), Marichuana (Coscojuela de Fantova, Huesca), Marimingo (Bullas, Murcia), Marilozana (Jumilla, Murcia), María la de Jacinto (Yecla, Murcia), María Roque (Cartagena,

\footnotetext{
${ }^{1}$ La conversión de un topónimo en antropónimo es muy frecuente. En el caso de la lengua española no solo ocurre en el caso de los apellidos, sino también en el de los nombres de pila, del tipo Covadonga, Javier, Borja, Aránzazu, etc.
} 
Murcia), etc ${ }^{2}$. Con ser todo muy sencillo, muy claro y muy evidente, no lo es tanto el observar que en una amplia zona del territorio de habla actual castellana encontramos muchos casos en los que el segundo elemento que determina la forma hipocorística Mari- no es del todo claro que sea un apellido o un segundo elemento de Mari entendido como antropónimo. Se trata, como señalamos, de decenas de topónimos. Hemos elegido para esta breve apunte tan solo algunos ejemplos, procedentes de las provincias de Ávila, Cuenca, Guadalajara, Huesca, Murcia y Palencia: (1) Fuente de Mariguantes (Arenas de San Pedro, Ávila), (2) Fuente de Marifuentes (x3 Casavieja, Ávila; Arconada, Palencia; Villovieco, Palencia), (3) Alto de Maripez (Arbeteta, Guadalajara), (4) Mariagua (x2 Vega del Codorno, Cuenca; Moratilla de los Meleros, Guadalajara), (5) Marivalles (Burgohondo, Ávila), (6) Marimán (Tierz, Huesca), (7) Maricollás (Ansó, Huesca), (8) Marimota (Villarejo-Periesteban, Cuenca), (9) Mariguanas (Santa Eulalia La Mayor, Huesca), (10) Maribuena (El Tiemblo, Ávila), Cerro Maribueno (Peralveche, Guadalajara) (11) Maripinar (Cieza, Murcia), (12) Mariluenga (Santa María del Campo Rus, Cuenca), (13) Marihueso (La Serna, Palencia), (14) Altos de Marimezquita (Villastar, Teruel), (15) Marimantieles (Azañón, Guadalajara). A lo que parece algunos de estos topónimos se han extendido a la antroponimia, pues hay apellidos frecuentes derivados de antropónimos de este tipo, como es el caso de Marimón, que encontramos en zonas bastante extensas, aunque parece tener una cierta vinculación con el territorio de habla catalana ${ }^{3}$.

\section{POSIBILIDADES DE EXPLICACIÓN}

En general, puede afirmarse que, dada la "modestia", por así decir, de estos lugares que hemos señalado más arriba, nadie ha hecho, a nuestro conocimiento, ningún comentario o intento de exégesis. Una primera posibilidad que a nadie escapa consistiría en sostener que casos como los de Mariguantes, Maripez, Marimota, Marivalles, mucho más Maribueno, son iguales en todo a Marigómez, Marimingo, esto es, que tenemos el nombre propio Mari con el apellido añadido, aunque este apellido sea en estos casos mucho menos fre-

${ }^{2}$ Esta formación toponímica es muy antigua, pues la hallamos documentada abundantemente en el Libro de la Montería de Alfonso XI, del siglo XIV: El Colmenar de Maria Esteuan (268v/ 112b; XXII), Las Casas de María Domingo (140r/70a; VIII), Val de Maria [v. Marj] Franca (263r,v/110b; XXI), etc. Los datos proceden de Ruhstaller (1995). Debe de ser meramente fortuito, pero no aparece ningún ejemplo en este libro del modelo toponímico Mirafuentes.

${ }^{3}$ Hallamos una especial frecuencia del apellido en Baleares, Valencia y Cataluña. Con todo, en Santos de Maimona (Badajoz) existe el castillo de Marimón, aunque ignoramos detalles históricos sobre esta fortaleza. Puede tratarse de un traslado toponímico. 
cuente que en los casos anteriores. En el topónimo convertido en antropónimo Marimón sí hemos hallado un intento de explicación, pues Moll, en su conocida monografía sobre los apellidos catalanes ${ }^{4}$, señala que éste tendría un origen francés a partir de Miremont. La tradición oral, por lo demás, ha querido explicar este apellido como una supuesta aposición de los términos catalanes para "mar" y "monte", esto es, como *mar-i-mont, lo que se nos antoja bastante increíble.

Esta explicación de los hechos no es absolutamente imposible, pues ciertamente no es del todo inverosímil que una mujer llamada María haya tenido o tenga actualmente como apellido Guantes, Mezquita, Agua, Pez, Mota, Mantieles, Man, etc. Incluso es un hecho cierto que Bueno o Valles son frecuentes como apellido.

Con todo, creemos que es razonable mostrar un cierto escepticismo ante esta explicación, si no en todos los casos, sí, al menos, en la gran mayoría de los ejemplos que hemos citado. Sencillamente no es razonable creer que sean tantos los casos de apellidos inusuales unidos siempre a ese nombre, pues no hemos encontrado ningún ejemplo de estos supuestos apellidos unidos a otros antropónimos, incluso a antropónimos más frecuentes en la toponimia española, como los antropónimos masculinos Domingo, Mingo, Juan, Paco, etc.

Así las cosas, no parece del todo descabellado buscar otros orígenes para el primer elemento de estos topónimos. La búsqueda, como señalábamos al comienzo de esta breve nota, en este caso no es muy dificultosa. Creemos que, sencillamente, se trata de una forma Mira-, del verbo mirar, cuyas vocales han sufrido una curiosa metátesis hasta convertirse en Mari-. Podemos decir, si así se quiere, que se trata de una metátesis ocasional, pero frecuente, favorecida por la etimología popular, pues ciertamente sí hay muchos casos, como los que hemos señalado más arriba del tipo Marigómez, donde efectivamente el topónimo está compuesto del antropónimo femenino y un apellido.

La verosimilitud de esta hipótesis es grande cuando se analiza estos topónimos entendiendo el primer elemento como Mira- > Mari-. Aunque es cierto que algunos de ellos siguen siendo oscuros, la mayor parte de ellos puede entenderse y compararse muy claramente con otros topónimos que no hayan sufrido la metátesis y de cualesquiera otras regiones de la España de habla castellana.

\section{Fuente de Mariguantes, ALto de Maripez, Mariagua}

De esta manera, los topónimos que dan título a esta nota son ahora totalmente transparentes. El caso más interesante es quizá el de Fuente de Mari-

\footnotetext{
${ }^{4}$ Moll (1982: 168).
} 
guantes, en el que hay incluso una curiosa tautología, pues entendiendo Mariguantes como metátesis de *Miraguantes es evidente que el topónimo debe ser comparado con Mirafuentes ${ }^{5}$, toda vez que, como hemos tratado de mostrar en otro lugar ${ }^{6}$, -guantes es resultado de cast. fuentes, él mismo del lat. fontes. La aposición del antiguo topónimo *Miraguantes, convertido en Mariguantes, al sustantivo fuente deja las cosas más que claras, pues aunque es posible que una mujer llamada Mari tenga el apellido Fuentes parece una casualidad excesiva que precisamente el nombre la mujer llamada Mariafuentes haya dado lugar al nombre de una fuente. En todo caso, la presencia en la misma provincia de Ávila del topónimo Fuente de Marifuentes aleja cualquier duda en torno a este análisis y hace esa supuesta casualidad casi imposible.

En el caso de Alto de Maripez, entendido ahora como *Alto de Mirapez, observamos la presencia de dos elementos semánticamente muy vecinos como alto y mira. El complemento del verbo es aquí el sustantivo común pez, que hallamos en otros casos para significar algo así como 'río' en la toponimia española, como las formas sin metátesis Barranco de Miralpeis (Capella, Huesca), Miralpeix (Tiurana, Lérida), Mirapeix, etc ${ }^{7}$. En el caso de Mariagua (Vega del Codorno, Cuenca) la interpretación es similar a la de Maripez, esto es, se trata de un lugar que mira, está orientado hacia el agua, en este caso, obviamente, un río o un manantial.

De esta manera, mediante el entendimiento de una metátesis de Mira en Mari puede analizarse de forma satisfactoria el resto de los ejemplos que hemos citado más arriba.

En el caso de Marivalles (Burgohondo, Ávila) obviamente se trata de un lugar orientado hacia el valle, lo que es un tipo toponímico muy frecuente, del tipo Miravalles (Vizcaya), Miravall (Lérida), justamente lo contrario de lo que hallamos en los topónimos oscenses Marimán y Maricollás que pueden ser comprendidos bien mediante nuestra hipótesis, una vez tenida la cuenta la foné-

\footnotetext{
5 Topónimo frecuente para referirse a un lugar desde el que se vislumbra o ve unas fuentes, más en general, o cercano a unas fuentes, como Mirafuentes (Navarra).

${ }^{6} \mathrm{El}$ resultado guante, güente o su evolución fonética a partir del del lat. fonte es seguro y está presente en ejemplos del tipo Guanz (Loscorrales, Huesca), Os Guances (Gésera, Huesca), La Güente (Santa Coloma, La Rioja), Gobantes (Burgos), Otero de Naraguantes (Fabero, León). Básicamente se trata de un reforzamiento consonántico a partir de *huante, *huente $>*$ uante, *uente, con debilitamiento de /f/ inicial. El resultado con aspiración está mejor documentado, pues son centenares los ejemplos del tipo La Juambuena (Castilforte, Guadalajara), Juan Cerrada (Cifuentes, Guadalajara), Fuente de Juan Podrido (Valdesaz, Guadalajara), La Juan Podrida (Barrachina, Teruel), Juan Seco (Alcaudete, Jaén), etc. Detalles sobre la cuestión en Nieto (2000a y 2000b).

${ }^{7} \mathrm{La}$ imagen toponímica es frecuente, especialmente, en el dominio catalán y provenzal. Nuestro ejemplo muestra la presencia de la imagen en Guadalajara, lo que nos parece muy importante. El topónimo catalán se ha extendido también al ámbito antroponímico, pues el apellido Miralpeix no es raro. Puede verse detalles sobre este tipo toponímico en Coromines (1989-1997).
} 
tica de la zona. El segundo elemento de Marimán es muy posiblemente *man $(t)$ procedente de lat. monte con diptongación de /o/ en /wa/ y apócope final, como parece observarse en otros topónimos oscenses del tipo Comademán ( Burgasé $)^{8}$. El topónimo es así semejante en todo al muy común Miramón (Castejón de Monegros, Huesca) o Miramonte, paralelo y contrario, precisamente, a Marivalles. El apellido catalán Marimón que hemos mencionado en varias ocasiones más arriba es justamente igual. El significado de Maricollás puede ser el mismo, toda vez que entendemos -collás como procedente de *collars, siendo collar un colectivo de cuello en sentido orográfico, como en otros topónimos de la zona tales como Cuello Serrablo (Secorún, Huesca), Los Cuellos (Seira, Huesca), etc. Se integra quizá en esta serie también el conquense Marimota, entendiendo aquí en mota el sustantivo común que tantas veces hallamos en la toponimia de esta provincia?.

El modelo toponímico presente en Mariguanas es también frecuentísimo si se analiza según hemos señalado. Se trata, en efecto, en -guanas del común adjetivo bueno, buena con fonética de la zona, esto es, diptongación de /o/ abierta tónica en /wa/ y conversión de /b/ en /g/ ante /u/. La constatación de la verosimilitud del análisis viene de la comparación con otros topónimos del tipo Miralguana (Santa Eulalia La Mayor, Huesca), Miralbueno (Biscarrués, Huesca), etc. Debe entenderse, pues, *Mira-lo-bueno, *Mira-la-buena, modelo que encontramos extendido por todas partes: Miralbò (Sant Orenç, Ribagorza), Peña Mirabueno (Henche, Guadalajara), Mirabueno (Lorca, Murcia), Mirambuena (Martín del Río, Teruel), Mirambel (Teruel), etc. Naturalmente el análisis de Mariguanas como *Miraguanas sostiene el de Maribuena y Maribueno, que podrían ser en principio antropónimos puros, aunque esta posibilidad se ve mermada por la aposición a sustantivos que indican precisamente altura, como 'cerro' o similar.

De la misma manera, Maripinar en Cieza, Murcia, es más que probablemente Mirapinar, pues se trata de un "cabezo" y toponimos del tipo Mirapinar (Simancas, Valladolid), Mirapinos (Puente Duero-Esparragal, Valladolid), Miralpino (Puebla de Salvador, Cuenca), son muy claros ${ }^{10}$. También lo parece el conquense Mariluenga, pues justamente una "mira" permite mirar "luengo", a distancia, una mirada larga, como muestran topónimos que presentan estos dos elementos léxicos, del tipo Miraluengo (Tella, Huesca), En el caso de

\footnotetext{
${ }^{8}$ Compárese Monte Coma (Lanaja), Comapueyo (Sieste), Comapollo Barrau (Benasque), etc.

${ }^{9}$ Así, por ejemplo, Motilla del Palancar, Llanos de la Mota. Es más difícil verlo en casos como Moltuenga (La Peraleja), con metátesis una vez producida la síncopa en *motaluenga. Compárese, con alteración por asociación con los muchos compuestos en mont-, el segoviano Montuenga.

${ }^{10}$ Puede ser de interés aquí Marinogales (Villaprovedo, Palencia), en donde -nogales puede ser apellido del antropónimo Mari, pero también cabe que debamos entender *Miranogales.
} 
Marihueso tenemos más problemas, pero creemos que es razonable entender Mirahueso, aunque este segundo elemento -hueso no estamos seguros de si es el sustantivo común hueso, con lo que aquí se nos referiría a un antiguo cementerio o enterramientos, o bien si se trata de una variante masculina de la forma huesa (<lat. fossa), en el sentido de 'fosa, terreno excavado', de la misma manera que en castellano actual se ha generado un masculino foso a partir de la forma femenina fosa. La toponimia nos muestra muchos ejemplos de huesa y de hueso, huesos: La Huesa (Cardeña, Córdona), Fuente de la Huesa (Higuera la Real, Badajoz), Huesos (Jerez de los Caballeros, Badajoz), El Hueso (Valderrábano, Palencia), etc. Constatamos la existencia de casos como Manantial Mirahueso (Vitoria, Álava), que parecen hablar a favor de nuestra interpretación de los hechos.

No obstante, en este rápido elenco que hemos trazado de ejemplos en los que un antiguo Mira- ha sido convertido en Mari, no hemos querido dejar de lado algunos casos en los que no se ve con igual facilidad el significado y el segundo componente del topónimo aunque hayamos analizado correctamente, según creemos, el primero. Parece correcto entender Marimezquita y Marimantieles como *Miramezquita y *Miramantieles, fundamentalmente porque Marimezquita aparece como Altos de Marimezquita y hallamos el topónimo simple Mezquita en ejemplos de la zona, del tipo Barranco de la Mezquita (Báguena, Teruel), La Mezquita (Molinos, Teruel), La Mezquitilla (Orrios, Teruel) y porque en el caso de Marimantieles hallamos el simple Mantiel (Guadalajara). Así pues, también Marimantieles podría significar 'que mira a Mantieles', 'encarado hacia Mantieles', independientemente de qué es exactamente Mantiel, lo que no vemos del todo claro ${ }^{11}$.

\section{CONClusiones}

Así pues, parece que puede afirmarse que hay muchos topónimos de una amplia zona de España con un primer elemento de compuesto Mira-, que constituye el verbo que rige un objeto en un compuesto de rección verbal. Este primer elemento había sufrido un fuerte desgaste semántico y se había convertido, al menos en algunos casos, en casi un elemento preposicional, con el sentido de 'orientado a, hacia, en dirección a'. Este primer elemento verbal ha sido cambiado en Mari- en unas cuantas decenas de ejemplos, de los cuales se ha elegi-

${ }^{11}$ La forma Mantiel parece un diminutivo mozárabe en -iel, de los que tanto abundan, frente al castellano -illo, pero no entendemos bien el sustantivo presente, que parecería ser manto o algo similar. Puede ser útil, con todo, comparar otros topónimos como Villamanta (Madrid), que no entendemos. 
do en esta nota una selección. La metátesis vocálica es un hecho posible en términos lingüísticos estrictos, pero en este caso ha desempeñado un papel importante lo que denominamos usualmente "etimología popular", un factor que si es importante en la evolución general de la lengua lo es más aún en el caso de los topónimos. Esta "etimología popular" entronca directamente con una tradición popular, basada ciertamente en un hecho real, cual es la presencia abundante en la toponimia de antropónimos. Estos antropónimos en usos toponímicos son sentidos como tales por los hablantes mientras tienen uso en la denominación personal, y éste es, desde luego, el caso de los centenares de topónimos que, efectivamente, contienen el nombre María, Mari, uno de los más frecuentes como nombres de mujer.

Conocíamos ya casos muy semejantes en la toponimia hispánica. Al menos en dos casos el azar de la evolución fonética, favorecido sin duda por esta misma etimología popular a la que hemos hecho mención, había hecho que halláramos topónimos con un elemento Juan y un elemento Paco que debían ser distinguidos de aquellos otros que contienen, en efecto, los antropónimos Juan y Paco. En el primero de los casos se trataba de uno de los resultados posibles de lat. fonte. El resultado Juan se halla extendido en una amplísima zona de la España de habla castellana, que abarca la totalidad práctica de Castilla, Aragón, partes de Andalucía, etc., Encontramos decenas de ejemplos en los que el falso antropónimo Juan aparece unido a cualquier adjetivo femenino que pueda calificar a una fuente, del tipo La Juanjordana (Almonacid del Marquesado, Cuenca), Juan Santa (Campillos-Paravientos, Cuenca), La Juanseca (Campos del Paraíso, Cuenca), La Juanlengua (Cuenca) ${ }^{12}$, etc. En el segundo, de mucha menos importancia y extensión geográfica, encontramos un resultado local de lat. opacu, 'umbría, lugar sombreado', del tipo Paco Mundano (Jaca), Paco Alto (Aguas, Laguarta) y sobre todo, Paco Otajuán (Laguarta), topónimo oscense en el que es llamativa la unión de estos dos falsos antropónimos ${ }^{13}$. Si el análisis que hemos hecho en esta nota es correcto, a estos dos ejemplos se suma un tercero, el de Mari-, el primer caso de un antropónimo femenino que, de alguna manera, ha interferido en compuestos toponímicos de primer elemento Mira-. Naturalmente no se puede descartar que existan otros ejemplos similares, pues en la tradición popular que es la transmisión toponímica, sobre todo en topónimos menores como los aquí estudiados, la tradición de denominaciones personales tiene gran importancia.

\footnotetext{
${ }^{12}$ Esto es, "luenga" <lat. longa, metátesis frecuente, cf. Aldealengua (Salamanca).

${ }^{13}$ Para un estudio monográfico de este topónimo vid. Nieto (2000b).
} 


\begin{tabular}{|l|l|l|}
\hline \multicolumn{1}{|c|}{$\begin{array}{c}\text { SEGUNDO ELEMENTO } \\
\text { DEL COMPUESTO }\end{array}$} & \multicolumn{1}{|c|}{ MARI- } & \multicolumn{1}{c|}{ MIRA- } \\
\hline fuente & Marifuentes, Mariguantes & Mirafuentes \\
\hline pez, río, agua & Maripez, Mariagua & $\begin{array}{l}\text { Miralpeix, Miralpeis, } \\
\text { Mirapeix, Miraelrío }\end{array}$ \\
\hline monte, mota, cuello & $\begin{array}{l}\text { Marimán, Marimón, } \\
\text { Maricollás, Marimota }\end{array}$ & Miramón, Miramontes \\
\hline valle, llano & Marivalles & Miravalles, Miravall \\
\hline bueno,-a, bello, -a & Mariguanas, Maribuena & $\begin{array}{l}\text { Miralguana, Mirabueno, } \\
\text { Mirambuena, }\end{array}$ \\
\hline mezquita & Marimezquita & Manantial Mirahueso, \\
\hline hueso & Marihueso & Mirapinar, Miralpino \\
\hline pinar, nogal & Maripinar, Marinogales & \\
\hline
\end{tabular}

\section{BIBLIOGRAFÍA}

Coromines, Joan (1989-1997): Onomasticon Cataloniae. Els noms de lloc i noms de persona de totes les terres de llengua catalana, vol. 8, Barcelona, Curial Edicions Catalanes, pp. 280282.

Moll, Francesc de B. (1982): Els llinatges catalans (Catalunya, País Valencià, Illes Balears), $2^{\mathrm{a}}$ ed., Palma de Mallorca, Editorial Moll.

Nieto Ballester, Emilio (2000a): "La toponimia de las fuentes en España: una nota sobre algunos resultados del lat. fonte", Revista de Filología Española, 80, 3-4, pp. 395-406.

Nieto Ballester, Emilio (2000b): "Paco Otajuán (Laguarta, Huesca) y Otero de Naraguantes (Fabero, León). Una nota a propósito de una imagen toponímica”, en Benjamín García Hernández (ed.), Latín vulgar y tardío. Homenaje a Veikko Väänänen, Madrid, Ediciones Clásicas, pp. 209-219.

Ruhstaller, Stephan (1995): Materiales para la lexicología histórica. Estudio y repertorio de las formas léxicas toponímicas contenidas en el "Libro de la Montería" de Alfonso XI, Tübingen, Max Niemeyer Verlag.

Fecha de recepción: 1 de marzo de 2012

Fecha de aceptación: 7 de noviembre de 2012 